\title{
THE ISOLATION AND IDENTIFICATION OF HAEMOPHILUS SPP. FROM UNUSUAL LESIONS IN CHILDREN
}

\author{
BY \\ K. B. ROGERS, K. ZINNEMANN, AND W. P. FOSTER \\ From the Department of Clinical Pathology, Children's Hospital, Birmingham, and the Department \\ of Bacteriology, the University, Leeds
}

(RECEIVED FOR PUBLICATION FEBRUARY 28, 1960)

\begin{abstract}
From a high proportion of children sent to hospital $H$. influenzae can be isolated if suitable culture media are used. A number of $H$. influenzae strains were isolated from unusual sites, such as (1) blood cultures after tonsillectomy or tonsillotomy in five cases; (2) urine or the urinary tract in eight cases; (3) the lumen of appendices removed at operation in 11 cases $(4 \%)$; (4) osteomyelitis or pyarthrosis in six cases; (5) miscellaneous infections including two perianal abscesses, three cases of paronychia, one infected thyroglossal cyst, and several skin infections.

It is suggested that infections of the skeletal system and the urinary tract arise from haematogenous spread of $\boldsymbol{H}$. influenzae, as demonstrated by positive blood cultures after tonsillectomy and in two cases of skeletal infection. Infection of the appendix, perianal abscesses, paronychia, and skin infections probably arise by the direct route, either by immediate contact or by passage of viable organisms through the alimentary canal.
\end{abstract}

The routine bacteriological techniques that are used in the Birmingham Children's Hospital allow Haemophilus influenzae to be identified in any specimen except faeces. The species of Haemophilus that are the subject of this communication were isolated from children. There was no opportunity to examine similar material from adults. The purpose of this paper is to draw attention to the presence of species of Haemophilus in sites and lesions where these organisms are not usually expected or found.

\section{Methods and Materials}

Method of Isolation.- Specimens of pus, from any site, were seeded on heated blood (chocolate) agar plates, as well as on the "composite" blood agar plate described by Rogers and Heslop (1948). Heated blood agar plates were prepared by adding $10 \%$ of oxalated horse blood to heart infusion agar at about $60^{\circ} \mathrm{C}$.; after gentle mixing, the temperature was raised slowly to $75-80^{\circ} \mathrm{C}$. and maintained at that temperature for 10 minutes. (The colour of the mixture should then be that of milk chocolate and there should be no gross granularity or clumping.) The molten mixture was again mixed gently and poured into Petri dishes.

All inoculated heated blood agar plates were placed in large tin containers inside which a lighted small wax candle or night light was placed to supply a higher $\mathrm{CO}_{2}$ tension than found in normal atmosphere. The lid was sealed to the tins by a $\frac{2}{3}$ in. wide rubber elastic band. Pneumococci may require increased tension $\mathrm{CO}_{2}$ for growth (Gladstone and Fildes, 1940 ; Fleming, 1941), and the presence of this gas does not impede the isolation of $H$. influenzae. This simple device was employed for every routine culture normally incubated aerobically, except those on desoxycholate citrate agar, MacConkey's, Hoyle's tellurite, or Sabouraud's media.

Early subcultures of strains of $\boldsymbol{H}$. influenzae from an unusual situation were sent to Leeds for detailed identification, and typing where appropriate.

For the determination of $\mathrm{X}$ and $\mathrm{V}$ requirements, an autoclaved fresh or heated blood agar and an autoclaved yeastrel agar plate were used.

In the autoclaved blood agar plate the heat-labile $\mathrm{V}$ factor has been destroyed, while the heat-stable $X$ factor is still present. Autoclaved yeastrel agar, as prepared for colony counts of water supplies (Ministry of Health, 1956), contains neither X nor V. In our experience it is the only medium consistently free from any trace of $X$.

Both plates were seeded evenly with the Haemophilus strain under test. A staphylococcus was then streaked halfway across the inoculated area. Strains dependent on $\mathbf{X}$ factor alone grow all over the inoculated area of the autoclaved chocolate agar plate, while on the same medium strains requiring 
either $\mathrm{V}$ alone, or both $\mathrm{X}$ and $\mathrm{V}$, do not grow except as satellite growth in the vicinity of the staphylococcus streak. On the yeastrel agar plate only V-dependent strains show satellitism near the staphylococcus streak. Strains requiring either $\mathrm{X}$ only, or both $\mathrm{X}$ and $\mathrm{V}$, show no growth at all on yeastrel agar.

Type Identification.-For type identification, simple slide agglutination with the six type sera a to $f$ was employed as a screening test. Floccular precipitoagglutination, similar to that seen with pneumococcus types and their sera, occurs almost instantaneously. However, a slower, granular, non-type-specific agglutination may occur with some sera and strains and is probably due to somatic antigens and their corresponding antibodies. These non-specific reactions make the slide agglutination technique less than $100 \%$ reliable, and it is therefore essential to obtain confirmation by the Neufeld technique, or, if preferred, by the formal tube agglutination method.

For the Neufeld technique, Levinthal broth cultures should not be older than five or six hours, at which time capsules are fully developed, and type-specific polysaccharides from them have not yet gone into solution in the culture medium. The age of the Levinthal broth culture can be reduced considerably if 1-2 ml. of the medium is pre-warmed to $37^{\circ} \mathrm{C}$. before inoculation from an overnight chocolate or Levinthal agar plate immediately after the latter has been removed from the incubator. In this way the lag period is obviated. Capsules are well developed when the Levinthal broth culture shows the first signs of turbidity, i.e., after one or two hours if pre-warmed broth is used. Then a hanging drop preparation is made with (a) a loopful of the culture, (b) a loopful of type-specific $H$. influenzae antiserum, and (c) a discharged loop of Loeffler's methylene blue. The unstained capsules around the stained bacillary bodies are well defined when viewed through a microscope with corrected tube length. Cross reactions between $H$. influenzae types do not occur with the Neufeld technique or the formal tube agglutination.

Specimens.-Immediately before a tonsillectomy or tonsillotomy, a tonsillar swab and a blood culture were taken and another blood culture 3-4 min. after the operation. The blood samples were run into liquoid and were then transferred to a $0.15 \%$ glucose-
$1 \%$ peptone-infusion broth (Stuart, 1948). The removed tonsillar tissue was placed in a sterile Petri $\mathrm{d}$ :sh and the surface of the tissue was sterilized by searing. Then an incision was made with a sterile scalpel through the surface area thus sterilized and the fresh inner surface and depths of the crypts, exposed under sterile conditions, were cultured.

A few of the urinary strains were isolated from "clean" mid-stream specimens, but if $H$. influenzae was found in such circumstances a catheter specimen was taken, or at least a sample of urine obtained after scrupulous cleaning of the skin surrounding the meatus; from female children, a vaginal swab was taken at the same time.

\section{Results}

The strains of $\boldsymbol{H}$. influenzae isolated in this way are grouped under headings according to the sites in which they were found.

Blood Cultures Immediately Before and After Removal of Tonsils.-Thirty-eight patients were examined, of whom 19 had their tonsils removed by tonsillectomy. None of the pre-operative blood cultures grew any pathogens. Five of the postoperation blood cultures grew $H$. influenzae in pure culture.

Although cultures from the tonsils usually yielded a mixed growth of pneumococci, haemo lytic streptococci, and other mouth organisms besides $H$. influenzae, only $H$. influenzae was grown from the corresponding blood cultures. Four of the five strains were sent to Leeds for examination; three were not capsulated. One was a type b strain; both the pre-operative throat swab and the cultures from the tonsils of this child provided mixed growths which included noncapsulated $H$. influenzae. All colonies isolated from the tonsils and the throat of this case looked alike, but the presence of a few mucoid colonies in the cultures cannot be excluded, as a subculture from a single colony thought to be representative had been sent to Leeds for further examination.

TABLE I

ISOLATION OF ORGANISMS FROM BLOOD CULTURES AFTER TONSILLOTOMY AND TONSILLECTOMY

\begin{tabular}{|c|c|c|c|c|c|c|c|c|}
\hline \multirow{4}{*}{ Operation } & & \multirow{4}{*}{$\begin{array}{l}\text { No. of } \\
\text { Cases }\end{array}$} & \multicolumn{6}{|c|}{ Blood Cultu:e } \\
\hline & & & \multicolumn{3}{|c|}{ Pre-operative } & \multicolumn{3}{|c|}{ Post-operative } \\
\hline & & & \multicolumn{3}{|c|}{ Growth of } & \multicolumn{3}{|c|}{ Growth of } \\
\hline & & & Sterile & $\begin{array}{c}\text { Coagulase- } \\
\text { negative } \\
\text { Staphylococci }\end{array}$ & H. influenzae & Sterile & $\begin{array}{c}\text { Coagulase- } \\
\text { negative } \\
\text { Staphylococci } \\
\end{array}$ & H. influenzae \\
\hline $\begin{array}{ll}\text { Tonsillotomy } & \ldots \\
\text { Tonsillectomy } & \ldots\end{array}$ & $\begin{array}{l}\ldots \\
\therefore\end{array}$ & $\begin{array}{l}19 \\
19\end{array}$ & $\begin{array}{l}18 \\
17\end{array}$ & $\begin{array}{l}1 \\
2\end{array}$ & $\begin{array}{l}0 \\
0\end{array}$ & $\begin{array}{l}15 \\
16\end{array}$ & 1 & $\begin{array}{l}3 \\
2\end{array}$ \\
\hline Total ... & $\ldots$ & 38 & 35 & 3 & 0 & 31 & 2 & 5 \\
\hline
\end{tabular}


TABLE II

ISOLATION OF $H$. INFLUENZAE FROM TONSILS OF CASES IN WHICH THE ORGANISM WAS PRESENT IN THE BLOOD STREAM POST-OPERATIVELY

\begin{tabular}{|c|c|c|}
\hline $\begin{array}{l}\text { No. of Colonies of } \\
H . \text { influenzae Grown }\end{array}$ & $\begin{array}{l}\text { Pre-operative } \\
\text { Tonsillar Swab }\end{array}$ & $\begin{array}{c}\text { Post-operative } \\
\text { Cultures from Tonsils }\end{array}$ \\
\hline $\begin{array}{ll}\ldots & \ldots \\
\ldots & \ldots \\
\ldots & \ldots\end{array}$ & $\begin{array}{l}1 \\
2 \\
2\end{array}$ & $\begin{array}{l}2 \\
2 \\
1\end{array}$ \\
\hline
\end{tabular}

The results of the tonsillar cultures are summarized in Tables I and II. There were three positive blood cultures after tonsillotomy and two after tonsillectomy.

Urinary Cultures.-Eight children have been found to have urines infected with $H$. influenzae: none has been infected with $H$. parainfluenzae. Two of the eight children, from whom urine strains of $\boldsymbol{H}$. influenzae were isolated, had a recent and violent injury. Five others had congenital abnormalities of the urinary tract. In two a calculus of the pelvis of the kidney was found and one of these two children also had hydronephrosis. $\boldsymbol{H}$. influenzae was grown twice from catheter specimens and three times from clean specimens of one of these children (No. 3 in Table III).

Clinically it was noteworthy that sometimes $H$. influenzae was isolated from the urine of a child attending the hospital for the first time with what was thought to be an attack of uncomplicated pyelitis. Subsequently every one of these children returned with repeated urinary tract infections. On further investigation each of the children was found to have either renal calculi or congenital abnormalities of the urinary tract. The results are summarized in Table III.

One case deserves particular mention.

This boy had had both ureters transplanted into the colon at the age of 11 months because of a congenital ectopia vesicae. Four years later a stenosis of the right urethrocolic anastomosis developed and this was relieved by a plastic operation. Then a hydronephrosis of the right kidney developed and persisted. Six years later, at the age of 10 , the boy complained of pain in the right renal region. Radiographs showed that a calculus was present in the renal pelvis. The calculus was removed to preserve the kidney and to allow the ureter to be re-implanted in the colon at a later date. When the calculus was exposed, a swab was taken from the turbid fluid in the renal pelvis. This yielded a heavy growth of type 5 pneumococci and a moderate number of $\boldsymbol{H}$. influenzae. Cultures of the faeces failed to grow either of these organisms, although $E$. coli, green-forming non-haemolytic and Lancefield Group D haemolytic streptococci were isolated.

Cultures from Lumen of Appendices Removed at Operation.-For several years past, routine cultures have been made from the contents of appendices removed at operation for the purpose of identifying any Salmonella or Shigella strains (Rogers, 1957; White et al., to be published). At the same time, the contents of the appendices were treated as specimens of pus even if pus was absent, in an attempt to culture pyogenic organisms.

Eleven strains (Table IV) of non-capsulated $H$. influenzae were found in 327 appendices investigated in this way $(3.4 \%)$.

TABLE III

ISOLATIONS OF $H$. INFLUENZAE FROM URINARY TRACT

\begin{tabular}{|c|c|c|c|c|c|c|}
\hline No. & \multicolumn{2}{|c|}{$\begin{array}{l}\text { Sex } \\
\text { and Age }\end{array}$} & Abnormalities & $\begin{array}{l}\text { Catheter } \\
\text { Specimen }\end{array}$ & $\begin{array}{l}\text { Growth of } \\
H . \text { influenzae }\end{array}$ & Remarks \\
\hline 1 & $\mathbf{F}$ & 3 & $\begin{array}{l}\text { Hydioureter } \\
\text { Hydronephrosis }\end{array}$ & No & $\begin{array}{l}\text { Numerous non-capsulated } H . \\
\text { influenzae, few } E \text {. coli }\end{array}$ & $\begin{array}{l}\text { Microscopically many } H \text {. influenzae in urine } \\
\text { on first attendance at hospital. Further } \\
\text { attacks of urinary infection were due to } \\
\text { other organisms }\end{array}$ \\
\hline 2 & $\mathbf{M}$ & 3 & $\begin{array}{l}\text { Imperforate anus; recto- } \\
\text { vesicular fistula; per- } \\
\text { manent colostomy }\end{array}$ & $\begin{array}{l}\text { Yes, } \\
\text { through } \\
\text { indwelling }\end{array}$ & Heavy, pure & $\begin{array}{l}\text { Had had many attacks of tonsillitis, very ill } \\
\text { on admission }\end{array}$ \\
\hline 3 & $\mathbf{F}$ & 4 & $\begin{array}{l}\text { Bilateral hydroureter, } \\
\text { hydronephrosis }\end{array}$ & $\begin{array}{l}\text { catheter } \\
\text { Yes }\end{array}$ & Heavy, pure, non-capsulated & $\begin{array}{l}\text { Grown repeatedly from catheter specimens. } \\
\text { Patient's serum without agglutinins against } \\
\text { own } H \text { influenzae strain }\end{array}$ \\
\hline 4 & $\mathbf{F}$ & 5 & $\begin{array}{l}\text { Chronic pyelonephritis; } \\
\text { staghorn calculus }\end{array}$ & ," & $\begin{array}{l}\text { Heavy, together with a few coli- } \\
\text { form bacilli and occasional }\end{array}$ & $H$. influenzae predominant \\
\hline 5 & $\mathbf{F}$ & 12 & Bilateral hydronephrosis & ", & Heavy, pure, non-capsulated & Of many attacks of pyelitis only one due to \\
\hline 6 & $\mathbf{M}$ & 11 & $\begin{array}{l}\text { Bilateral hydronephrosis; } \\
\text { transplanted ureters; cal- } \\
\text { culus in pelvis of kidney }\end{array}$ & Direct & $\begin{array}{l}\text { Heavy, non-capsulated, mixed } \\
\text { with equal number of pneumo- } \\
\text { coccus type } 5 \text { colonies }\end{array}$ & Nephrostomy specimen; for details see text \\
\hline 7 & $\mathbf{F}$ & 9 & None; see "Remarks" & No & $\begin{array}{l}\text { Moderate, together with a few } \\
\text { coagulase-positive Staph. } \\
\text { aureus colonies }\end{array}$ & $\begin{array}{l}\text { Heavy } 6 \mathrm{ft} \text {. fall } 3 \text { days before admission, } \\
\text { heavy haematuria for } 10 \text { days; recovered } \\
\text { when treated as pyelitis }\end{array}$ \\
\hline 8 & $\mathbf{F}$ & 6 & Injury in kidney region & , & $\begin{array}{l}\text { Heavy, together with a few } \\
\text { colonies of } E \text {. coli and Staph. } \\
\text { albus }\end{array}$ & $\begin{array}{l}\text { Microscopically many pus cells and } H \text {. } \\
\text { influenzae in urine; developed dysuria }\end{array}$ \\
\hline
\end{tabular}


TABLE IV

B.ACTERIAL FLORA OF APPENDICES REMOVED FROM CHILDREN

\begin{tabular}{|c|c|c|c|c|c|c|c|c|c|c|c|}
\hline Year & $\begin{array}{c}E . \\
\text { coli }\end{array}$ & $\begin{array}{c}\text { Non-lactose } \\
\text { Fermenting } \\
\text { Bacilli } \\
\text { not } \\
\text { Salmonellae } \\
\text { or } \\
\text { Shigellae }\end{array}$ & $\underset{\text { Sal- }}{\text { monellae }}$ & Shigellae & $\begin{array}{c}\text { Strepto- } \\
\text { cocci } \\
\text { other than } \\
\beta \text {-Haemolytic }\end{array}$ & $\begin{array}{c}\text { Lancefield } \\
\text { Group F } \\
\text { Haemolytic } \\
\text { Strepto- } \\
\text { cocci }\end{array}$ & $\begin{array}{c}\text { Pneumo- } \\
\text { cocci }\end{array}$ & $\underset{\text { influenzae }}{H .}$ & $\begin{array}{c}\text { Staphylo- } \\
\text { cocci }\end{array}$ & $\begin{array}{c}\text { No } \\
\text { Gram- } \\
\text { negative } \\
\text { Bacilli } \\
\text { Isolated }\end{array}$ & $\begin{array}{l}\text { No. } \\
\text { Appen- } \\
\text { dices } \\
\text { Cul- } \\
\text { tured }\end{array}$ \\
\hline $\begin{array}{ll}1956 & \ldots \\
1957 & \ldots \\
1958 & \ldots \\
1959 & \ldots\end{array}$ & $\begin{array}{r}146 \\
79 \\
64 \\
45\end{array}$ & $\begin{array}{l}44 \\
14 \\
10 \\
44\end{array}$ & $\begin{array}{l}1 \\
0 \\
1 \\
0\end{array}$ & $\begin{array}{r}12 \\
2 \\
0 \\
2\end{array}$ & $\begin{array}{r}103 \\
31 \\
29 \\
30\end{array}$ & $\begin{array}{r}21 \\
14 \\
11 \\
5\end{array}$ & $\begin{array}{l}3 \\
4 \\
5 \\
2\end{array}$ & $\begin{array}{l}2 \\
2 \\
7 \\
4\end{array}$ & $\begin{array}{r}15 \\
3 \\
6 \\
0\end{array}$ & $\begin{array}{r}13 \\
4 \\
3 \\
2\end{array}$ & $\begin{array}{r}170 \\
90 \\
67 \\
49\end{array}$ \\
\hline Total & 334 & 72 & 2 & 16 & 193 & 51 & 14 & $15+$ & 24 & 22 & 376 \\
\hline$\%$ of total & 88.8 & $19 \cdot 1$ & 0.5 & $4 \cdot 3$ & $51 \cdot 3$ & $13 \cdot 6$ & 3.7 & $4 \cdot 0$ & 6.4 & $5 \cdot 9$ & \\
\hline
\end{tabular}

Table IV also shows not inconsiderable yearly fluctuations of the species isolated from the lumina of appendices.

Pneumococci were present in 12 specimens $(3.7 \%)$ often as the only other organism besides $H$. influenzae. The satellite phenomenon and absence of antagonism between the two organisms was noted consistently. The types of pneumococci found were 4 (1), 6 (2), 9 (3), 19 (2), 23 (2), 34 (1), and 35 (1), the figures in brackets indicating the number of strains of each type isolated.

Pus in Sites Unconnected with Respiratory, Alimentary, or Urinary Tracts.-Abscesses and osteomyelitis and pyarthrosis furnished the specimens.

Abscesses. - Non-capsulated strains of $H$. influenzae were isolated in nearly pure culture from two perianal abscesses, where they probably arrived via the gastrointestinal tract in the same way as the organism was thought to have reached the lumina of the appendices. Pure growth of $H$. influenzae was obtained from pus of an infected thyroglossal cyst.

A comparatively rare species of the genus Haemophilus, $H$. parahaemolyticus, which is sometimes found in acute tonsillitis and subacute endocarditis (Pittman, 1953), was isolated, together with coagulase-positive Staphylococcus aureus and albus, from an abscess under the left mandible in a boy aged 15 months. The dental surgeon who incised the abscess stated: "The infection obviously comes from the mandible as bare bone was easily palpable through the incision."

In 1929, Fleming reported the isolation of $H$. influenzae from septic wounds. Similarly we succeeded on several occasions in its isolation in mixed culture from infected skin, also from the pus of paronychiae. One was from the finger of a boy aged 6 years, when non-capsulated $H$. influenzae was present together with Staphylo- or coccus aureus and Strep. pyogenes. In another $\overrightarrow{0}$ similar case, a boy of 4 years, non-capsulated 을 $H$. influenzae was isolated together with haemo- lytic streptococci of Lancefield's group $F$, which normally is a commensal in the nasopharynx (Long and Bliss, 1934 ; Hare and Maxted, 1935). It is interesting to note that both these boys were finger suckers. A third paronychia yielded a mixed culture of Staphylococcus aureus and 8 non-capsulated strain of $\boldsymbol{H}$. influenzae.

Osteomyelitis and Pyarthrosis.-There were three cases of osteomyelitis of long bones, one with osteomyelitis of the tibial end of the knee and two with pyarthrosis infection in the hip joint, and $\Phi$ also one child with osteomyelitis of the os calcis. Two children had an acute pyarthrosis of the hip, in all six cases with involvement of bones or joints. One of the cases of pyarthrosis of the hip was caused by a non-capsulated strain of $H$. influenzae: and a second non-capsulated strain was isolated from a case of osteomyelitis of long bone, but in $\frac{0}{3}$ this case the presence of a capsule initially cannot be ruled out because, owing to the long holiday period, the strain was subcultured for several $₹$ weeks before it could be typed. From all other 의 cases, $H$. influenzae type $b$ was isolated, and this type was also recovered from the blood cultures을. of two of the children, one with pyarthrosis of the hip, the other with osteomyelitis of the tibial end ? of the knee joint.

\section{Discussion}

From these observations the question arises howe $H$. influenzae, which is a pathogenic organism of $\mathcal{\infty}_{\overparen{D}}$ the upper, and sometimes the lower, respiratory? tract, could establish itself in the situations from $\frac{0}{3}$ which it was isolated. The literature on $H$. influenzae meningitis and epiglottitis makes it clear $\stackrel{\mathbb{D}}{\mathbb{D}}$ 
that invasion of the blood stream by $H$. influenzae is not such a rare occurrence as one might be led to believe (Zinnemann, 1960). Once $H$. influenzae has been carried by the blood stream to a tissue with lowered local resistance, establishment of a focus of infection is a possible consequence.

Thus the strains of $H$. influenzae isolated from urinary tract infections in children with either congenital abnormalities of the urogenital system or with stone formation in the pelvis of the kidney cannot have reached these loci minoris resistentiae except as a reult of a transient bacteraemia. The work of Rocha, Guze, Freedman, and Beeson (1958) and Freedman and Beeson (1958) offers an explanation of unusual susceptibility of the kidney to infection and in particular of the increased vulnerability of damaged kidneys. They showed that when the renal medulla was damaged the nephrons draining through that part of the kidney were particularly susceptible to a pyogenic infection if a bacteraemia recurred. Albright, Dienes, and Sulkowitch (1938) also reported repeated isolation of $\boldsymbol{H}$. influenzae from the urine of two adults suffering from pyelonephritis and nephrocalcinosis. Thus the identification of $H$. influenzae in an infected urine indicates the need for detailed investigation of the patient to exclude the presence of abnormalities. The case in which turbid fluid obtained at nephrostomy contained non-capsulated $H$. influenzae and a pneumococcus type 5 emphasizes the pathogenesis of such infections of the urinary tracts, because there can be no doubt that this specimen came from the kidney.

One of the ways in which such infections can start has been demonstrated by the finding of $H$. influenzae in blood cultures after removal of the tonsils. The isolation of $H$. influenzae from blood cultures taken after such operations was somewhat unexpected, because Okell and Elliott (1935) never isolated $\boldsymbol{H}$. influenzae in any of their positive blood cultures before or after tooth extractions, although they isolated more than one organism on several occasions, and Ross and Rogers (1943) isolated streptococci but not $H$. influenzae after root canal instrumentation of infected but viable teeth. Our findings were all the more surprising because a selective bacteraemia must have taken place, for on several occasions only a few colonies of $\boldsymbol{H}$. influenzae were present in either pre- or post-operative tonsillar swabs together with other more numerous microorganisms. However, $\boldsymbol{H}$. influenzae could always be isolated from either the pre- or post-operative tonsillar swab or culture when it was found in the blood stream after tonsillectomy. We know only one report in the literature that bears on this point, a case reported by Clarke (1912), of a girl aged 13 with chronic, intermittent otitis media due to $H$. influenzae, who developed septicaemia and osteomyelitis following tonsillectomy.

The case of Clarke also demonstrated for the first time that infection of the skeletal system with $H$. influenzae can be traced back to bacteraemia. There are only a few references in the literature to osteomyelitis and pyarthrosis due to $H$. influenzae. The 31 cases reported between 1899 and 1938 have been reviewed by Weaver and Sherwood (1938), who added two cases of their own. Both these, one an adult coloured woman and one a coloured child of 18 months, had pyarthrosis. In 1947, Hirsch and Nassau described one case with osteomyelitis and abscesses of the subcutaneous tissue ; this was due to untyped $H$. influenzae and followed an acute febrile pharyngitis within four days. In the era before the advent of antibacterial drugs Weaver and Sherwood (1938) could point out that when osteomyelitis or pyarthrosis was preceded, accompanied, or followed by meningitis due to $H$. influenzae survival could not be expected, whilst practically all cases suffering only from $H$. influenzae infection of the skeletal system recovered, usually with a high degree of mobility. Antibiotics and sulphonamides have changed the prognosis of meningitis due to $H$. influenzae so much that nowadays a case fatality rate of more than $4 \%$ is regarded as a reason for a review of therapeutic procedures (Zinnemann, 1960).

It is suggested that a different mechanism operates when $\boldsymbol{H}$. influenzae establishes itself as the cause of infection in an appendix or causes a perianal abscess. Although infection of the blood stream cannot be ruled out, the direct route via the upper respiratory and the alimentary tracts seems more plausible, particularly if one assumes that micro-organisms enveloped in a ball of highly viscous mucus or mucopus, which is a characteristic of $\boldsymbol{H}$. influenzae infections, may pass the zones of gastric and duodenal digestion unharmed. Fleming (1929) previously isolated $H$. influenzae from the faeces. Two groups of Australian workers have published evidence to support their contention that oropharyngeal secretions reached the intestines. Anderson and Langford (1958) isolated three strains of $H$. parainfluenzae out of 12 jejunal specimens aspirated from normal children and three from 15 children with coeliac disease. Bishop and Allcock (1960) examined fluid aspirated from the small intestine above obstructions; from 27 patients they isolated two strains of $H$. parainfluenzae and $H$. aphrophilus. Neither of these groups isolated any strain of 
$\boldsymbol{H}$. influenzae or $\boldsymbol{H}$. parahaemolyticus. Hare and Maxted (1935) recovered Streptococcus pyogenes from the faeces of cases of scarlet fever, which findings tend to support the assumption of respiratory organisms passing through the alimentary tract in a viable state.

The isolation of $H$. influenzae from a skin lesion was reported by Fleming in 1929; he used penicillin incorporated in culture media for its isolation. Penicillin was not a constituent of the routine nutrient media used in this investigation, and it is possible that some strains from this site have been missed. On the special blood agar plates used (Rogers and Heslop, 1948), the solution of 1 in 10,000 gentian violet, which is spread over the outer segments, nearly always inhibits $H$. influenzae. This inhibition is helpful in the identification of $H$. influenzae. Inhibition of $H$. influenzae also takes place at a 50 times higher dilution of gentian violet, which is the concentration of the dye in Garrod's blood agar plate (1942). These observations are not in accord with the findings of Bernstein and Loewe (1919) or of Masters, Brumfitt, Mendez, and Likar (1958), who used gentian violet in solid media to facilitate the isolation of $\boldsymbol{H}$. influenzae.

It is important that the isolation of $H$. influenzae in unusual sites should be seen in perspective. For

TABLE V

SUR VEY OF NUMBER AND PERCENTAGE OF STRAINS OF $H$. INFLUENZ AE ISOLATED FROM ROUTINE SPECIMENS DURING 1957 AT THE CHILDREN'S HOSPITAL, BIRMINGHAM

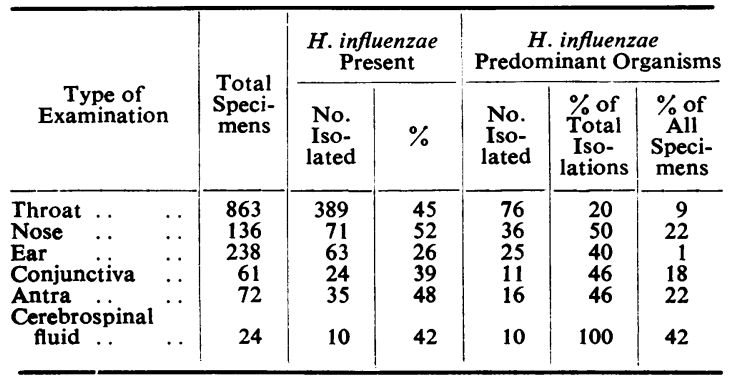

this reason a survey of the number of strains isolated from other routine specimens during 1957 at the Children's Hospital is given in Table V.

Only the 10 strains of $H$. influenzae isolated from cerebrospinal fluid were typed; all were of type b. The other 582 strains were not so examined. These figures are presented to show how frequently $H$. influenzae is found in children attending hospital.

If routine cultures are made with a technique that permits the growth of $\boldsymbol{H}$. influenzae, then the results obtained in Birmingham and reported here probably would be a common experience. In this sense we do not regard our findings as exceptional.

We are pleased to acknowledge the help of Dr. J. Boissard, who confirmed the identity of the early strains of Group F haemolytic streptococci ; to Drs. G. M. Williamson and Ann W. Cooper for identifying some strains when one of us was absent; to Mr. Guy Baines, who has allowed us to report the child from whom the nephrostomy specimen was obtained; to Mr. G. S. Hoggins for permission to describe the case infected with $H$. parahaemolyticus; and to Mrs. D. Clarke for technical assistance.

\section{REFERENCES}

Albright, F., Dienes, L., and Sulkowitch, H. W. (1938). J. Amer.

med. Ass., 110, 357.
Anderson, C. M., and Langford, R. F. (1958). Brit. med. J., 1, 803 Bernstein, E. P., and Loewe, L. (1919). J. infect. Dis., 24, 78. Bishop, R. F., and Allcock, E. A. (1960). Brit. med. J., 1, 766. Clarke, J. M. (1912). Lancet, 1, 1465.

Fleming, A. (1929). Brit. J. exp. Path., 10, 226.

- (1941). Lancet, 1, 110.

Freedman, L. R., and Beeson, P. B. (1958). Yale J. Biol. Med., 30 406.

Garrod, L. P. (1942). Brit. med. J., 1, 290.

Gladstone, G. P., and Fildes, P. (1940). Brit. J. exp. Path., 21, 161

Hare, R., and Maxted, W. R. (1935). J. Path. Bact., 41, 513.

Hirsch, W. and Nassau, E. (1947). Ann. paediat. (Basel), 168, 289.

Long, P. H., and Bliss, E. A. (1934). J. exp. Med., 60, 619.

Masters, P. L., Brumfitt, W., Mendez, R. L., and Likar, M. (1958) Brit. med. J., 1, 1200.

Ministry of Health (1956). The Bacteriological Examination of Water Supplies. Rep. on Publ. Hlth and Med. Subj. No. 71, 3rd ed. H.M. Stationery Office, London.

Okell, C. C., and Elliott, S. D. (1935). Lancet, $2,869$.

Pittman, M. (1953). J. Bact., 65, 750.

Rocha, H., Guze, L. B., Freedman, L. R., and Beeson, P. B. (1958). Yale J. Biol. Med., 30, 341.

Rogers, K. B. (1957). Proc. roy. Soc. Med., 50, 1025.

and Heslop, W. (1948). J. clin. Path., 1, 315.

Ross, W. S., and Rogers, K. (1943). Brit. dent. J., 74, 253.

Stuart, R. D. (1948). J. clin. Path., 1, 311.

Weaver, J. B., and Sherwood, L. (1938). Surgery, 4, 908.

Zinnemann, K. (1960). Ergebn. Mikrobiol., 33, 307. 